\title{
Evaluation of Safety and Efficacy of Combined Low Dose Aspirin and Warfarin Following Mechanical Heart Valve Replacement for Mitral Valve Disease
}

\author{
Md Sorower Hossain ${ }^{1}$, Istiaq Ahmed², Sanjay Kumar Raha ${ }^{3}$, Smriti Kana Biswas ${ }^{4}$, Md Kamrul Hasan ${ }^{5}$
}

\begin{abstract}
:
Introduction: Warfarin is recommended following mechanical valve replacement to prevent thromboembolic complications. A combination of warfarin and aspirin may further reduce thromboembolic events in these patients. This study was designed to evaluate safety and efficacy of combined low dose aspirin and warfarin therapy following mechanical mitral valve replacement.

Materials and Methods: Purposively selected 99 patients who underwent mechanical mitral valve replacement were divided into two groups. Patients of Group A $(n=50)$ received combined low dose aspirin $(75 \mathrm{mg})$ and warfarin. Patients of Group B $(n=49)$ received conventional dose of warfarin alone. International normalized ratio (INR) was targeted 1.8-2.4 for group A Patients and 2.5-3.5 for group B Patients. Post-operatively INR, thromboembolic events, anti-coagulation related haemorrhage and other morbidity and mortality were registered in both groups.
\end{abstract}

Result: Patients were followed up postoperatively for 9 months. The mean dose of warfarin in group $A$ and group $B$ was $4.36 \pm 0.31 \mathrm{mg}$ and $5.57 \pm 0.52 \mathrm{mg}$ respectively $(p<0.001)$. The overall mean INR of two groups of patients were statistically different $(P<0.001)$ with low INR in group $A$ (2.19 \pm 0.13$)$ patients compared to group $B(3.03 \pm 0.31)$. The thromboembolic events in group $A(0.02 /$ patient year) were lower than those in group $B(0.08 / P a t i e n t ~ y e a r)$. There was no statistically significant $(p=0.362)$ difference in bleeding episodes between two groups but data indicate proportion of minor bleeding manifestations were higher in patients treated with warfarin plus aspirin group.

Conclusion: Following mechanical mitral valve replacement, a combination of aspirin $(75 \mathrm{mg})$ and low dose warfarin with an aim to maintain INR between 1.8 and 2.4 (lower than recommended 2.5-3.5) may provide satisfactory outcomes in term of thrombosis, embolism and bleeding without increase in mortality.

Keywords: Warfarin, Aspirin, Mitral valve replacement, Thromboembolism, Anticoagulation related haemorrhage.

(Bangladesh Heart Journal 2021; 36(1): 24-31)

Introduction:

Mitral valve diseases (stenosis and regurgitation) are surgically correctable mechanical problems of the heart. Surgical options are repair and replacement with either bioprosthetic or mechanical prosthetic valves. The most common mitral valve surgery is the replacement of the valve with the mechanical prosthetic valve. ${ }^{1}$ Cardiac

1. Assistant Registrar, Department of Cardiac Surgery, National Institute of Cardiovascular Diseases, Dhaka, Bangladesh.

2. Associate Professor, Department of Cardiac Surgery, Dhaka Medical College and Hospital, Dhaka, Bangladesh.

3. Associate Professor, Department of Cardiac Surgery, National Institute of Cardiovascular Diseases, Dhaka, Bangladesh.

4. Assistant Registrar, Surgery Outpatient Department, National Institute of Cardiovascular Diseases, Dhaka, Bangladesh.

5. Professor, Department of Cardiac Surgery, National Institute of Cardiovascular Diseases, Dhaka, Bangladesh.

Address of Correspondence: Md. Sorower Hossain, Assistant Registrar, Department of Cardiac Surgery, National Institute of Cardiovascular Surgery, Dhaka, Bangladesh. Email: Sorowercts@gmail.com, Mobile: +8801711165186.

DOI: https://doi.org/10.3329/bhj.v36i1.55514

Copyright (@) 2017 Bangladesh Cardiac Society. Published by Bangladesh Cardiac Society. This is an Open Access articles published under the Creative Commons Attribution-NonCommercial 4 .0 International License (CC BY-NC). This license permits use, distribution and reproduction in any medium, provided the original work is properly cited and is not used for commercial purposes. 
prostheses can cause peripheral and cerebral thromboembolism or can develop valve thrombosis; all are devastating complications. ${ }^{2}$ In last 20 years, there were dramatic improvements in the reduction of morbidity of patients with prosthetic heart valves. However, thromboembolism still occurs in up to $2 \%$ of patients per year. ${ }^{3}$

Valvular thrombosis is not unique to mechanical prostheses, and it probably has a multifactorial etiology. With surgical technique, patient related factors, anticoagulation control and prosthesis design all playing a part; prosthesis design however, is perhaps the most important factor. These same factors also may influence the incidence of thromboembolic events, many of which are probably attributable to embolization of platelet aggregates rather than thrombus. ${ }^{4}$ It is well recognized that with artificial devices in the bloodstream particularly prosthetic heart valves, platelet survival time decreases significantly and correlates closely with increased platelet activation and deposition. However, for the mitral prostheses, slow flow across the valve and large left atrium leading to stasis and prolong contact of coagulation factors with the prostheses is the primary cause of thromboembolism whereas platelet factors are the secondary contributory factor. ${ }^{2}$

Oral anticoagulation therapy plays an important role in the prevention of thromboembolic events. So, warfarin is prescribed lifelong following mechanical valve replacement. ${ }^{1}$ However, the risk is reduced but not eliminated by the long-term administration of standardintensity oral anticoagulant therapy. ${ }^{5}$ Moreover it itself carries a significant bleeding hazard. ${ }^{6}$ The incidence of bleeding complication varies with the quality and range of anticoagulation control. ${ }^{4}$ Warfarin therapy is maintained following the prothrombin time (PT) and international normalized ratio (INR) ${ }^{7}$

A combination of warfarin and an antiplatelet agent such as aspirin may further reduce thromboembolic complications in patients with prosthetic heart valves. Though the risk of thromboembolism is lower in patients receiving combined aspirin and oral anticoagulation therapy, the risk of major bleeding is higher than in patients receiving anticoagulation therapy alone. This increased bleeding risk seems to be related to the dose of aspirin, as lower dose of aspirin is associated with a reduced risk of major bleeding when used together with warfarin. ${ }^{1}$

American College of Chest Physicians guidelines 2001 recommended an INR of 2.5 to 3.5 for patients with mechanical prosthetic valves and of 2.0 to 3.0 for those with bioprosthetic valves and low risk patients with bileaflet mechanical valves (such as the St. Jude Medical device) in aortic position. Similar guidelines have been promulgated conjointly by the American College of Cardiology and American Heart Association. ${ }^{8}$

Different comparative studies that analyzed anticoagulant intensities has revealed that thromboembolic and hemorrhagic complications are less prevalent with an intensity of oral anticoagulation below the recommended therapeutic ranges. However, the safety and efficacy of lower intensity anticoagulant have not proven so far. ${ }^{6}$

Because of uncertainty about the true intensity of anticoagulation, some patients were being anticoagulated at unnecessary high intensity and exposed to greater risk of bleeding. Although not fully worked out, for all types of mechanical and thrombotic risk factors, because of lack of data, there is now widespread acceptance of the principle that the target INR should be both prosthetic specific and patient specific. In general, there has been a lowering of recommended INR for low thrombogenicity prosthesis in recent years with an associated reduction in the risk of serious bleeding. ${ }^{9}$

As a means of improving the efficacy of antithrombotic therapy after cardiac valve implantation, anticoagulation has been augmented with an antiplatelet agent. Although the results of some of the trials have been encouraging, showing improved effectiveness with no substantial increase in bleeding risk, the results are far from consistent. ${ }^{6}$

Butchart et al. ${ }^{4}$ in a review of embolism in prosthetic heart valves concluded that valves vary in susceptibility to thrombosis due to subtle design differences, that optimal INR range is often uncertain, and further research is needed.

American College of Cardiology / American Heart Association (ACC/AHA) guidelines 2001 had given messages that the addition of low dose aspirin (80 to $100 \mathrm{mg}$ ) to warfarin therapy not only decreases the risk of thromboembolism but also decreases mortality due to other cardiovascular diseases if INR is maintained within the target range with aspirin though there might be slight increase in the risk of bleeding with this combination. 8

With higher INR levels the risk of bleeding related complication increases in ever increasing ratio. If addition of aspirin allows us to reduce the INR levels without sacrificing safety and efficacy of prosthetic valve, it will render us greater safety margin and thus reduce morbidity 
and cost of treatment. This study is designed to evaluate safety and efficacy of combined low dose aspirin and warfarin following prosthetic mechanical heart valve replacement in mitral position.

\section{Materials and Methods:}

This prospective cohort study was conducted in the Department of Cardiac Surgery, National Institute of Cardiovascular Diseases, during the time period from July 2015 to March 2018. 99 adult patients who underwent mitral valve replacement were purposively selected. Patients having history of thromboembolic events, preoperative atrial fibrillation, major non-cardiac progressive diseases and aspirin hypersensitivity were excluded from the study. They were divided into two groups: a) Group A: Patients receiving combined low dose aspirin (75mg) and warfarin (target INR 1.8-2.4) and b) Group B: Patients receiving conventional dose of Warfarin (target INR 2.5 -3.5)

Demographic variables (e.g. age, sex), clinical variable (e.g. NYHA class), haematological parameters, chest xray and echocardiographic were taken into account for evaluation of all patients. Coronary angiography was done in selective cases to exclude coronary artery occlusion in patients having symptoms of angina, strong positive family history and age more than 40 .

All the patients were operated in the Department of Cardiovascular Surgery, National Institute of Cardiovascular Diseases. Through a standard median sternotomy, cardiopulmonary bypass was instituted using ascending aortic and bicaval cannulations vent passed. Patient's temperature was cooled to 32 degree centigrade. Following which, aorta was cross-clamped. Then antegrade cardioplegia was given and heart was arrested. Left atriotomy was done. Mitral leaflets were excised so as to remove the scarred and calcified tissue. A valve sizer was used to determine the proper diameter of the prosthetic valve. Supra-annular pledgeted mattress sutures were placed sequentially around the mitral annulus. The valve sutures were passed sequentially through the sewing ring of the prosthetic valve. The valve was seated and sutures are tied. The most recent FDA approved least thrombogenic St. Jude Medical bi-leaflet mechanical valve was used in all patients. Then the valve leaflets were gently opened with valve tester to inspect proper opening of prosthetic valve. Left atriotomy was closed with 4/0 round body polypropylene and air was vented and patient weaned gradually off the Cardiopulmonary Bypass. After ensuring meticulous hemostasis, drain tubes were placed in the retrosternal and retro-cardiac part of the pericardial cavity. If required, separate pleural chest drain was placed and chest was closed in layers.

\section{Post-operative evaluation:}

Following the surgical procedure all the patients were brought to the cardiovascular intensive care unit where they were monitored until the patients were extubated and till stabilization of the respiratory and hemodynamic status. Aspirin and warfarin were commenced within 48 hours of the surgery, when patients were stabilized and chest drainage fluid volume was $<50 \mathrm{ml}$. Then the patients were transferred to the ward for the routine care. Prothrombin time and INR were done on the $3^{\text {rd }}$ morning after starting warfarin. Then they were repeated twice weekly until target INR was achieved before discharge. The patients were then discharged from the ward and advised for subsequent follow up.

Patients attended at follow up clinic on the $1^{\text {st }}, 2^{\text {nd }}, 3^{\text {rd }}$, $6^{\text {th }}$ and $9^{\text {th }}$ month after discharge with INR results. During follow up, patients were evaluated clinically. Warfarin doses were adjusted to achieve target. Echocardiographic evaluations were done on $1^{\text {st }}, 3^{\text {rd }}$ and $9^{\text {th }}$ month to determine the functional status of valve, paravalvular leakage, and prosthetic valve endocarditis and valve thrombosis.

\section{Data collection}

All data were collected from each patient using predesigned questionnaire and collection form. Data were analyzed and verified with statistical program for social sciences (SPSS) using student's t test, fisher's exact test, chi-square test, where appropriate. The descriptive statistics used here were frequency, mean and standard deviation (SD) and compared using student's t test. Categorical data were expressed as percentages and evaluated using Chi-square or Fischer's exact probability test. The level of significant was 0.05 . Any p-value $<0.05$ was considered as significant.

\section{Result:}

Age distribution of the study population

The mean age of the group A patients was 35.18 \pm 10.59 years and that of group B patients was $32.94 \pm 8.81$ years. However, analysis revealed no statistically significant mean age difference between two groups $(p>0.05)$.

\section{Sex distribution of the study population}

In group A $58 \%$ were female and $42 \%$ were male. But the sex distribution of group B showed a male (53.1\%) predominance. Analysis found no statistically significant sex difference between two groups $(p>0.05)$. 


\section{Distribution of the study population according to diagnosis}

Both the groups showed similar pattern of disease, mostly mitral stenosis ( $50 \%$ vs. $49 \%$ ), followed by mitral regurgitation ( $26 \%$ vs. $28.6 \%)$ and then combined pathology $(24.0 \%$ vs. $22.4 \%)$.

\section{Distribution of Post-operative INR at Follow Up}

The mean INR of Group A the patients at the time of discharge was $2.25 \pm 0.44$. Subsequently it was $2.13 \pm$ 0.39 at $1^{\text {st }}$ month, $2.10 \pm 0.37$ at $2^{\text {nd }}$ month, $2.20 \pm 0.46$ at $3^{\text {rd }}$ month, $2.13 \pm 0.38$ at $6^{\text {th }}$ month and $2.34 \pm 0.46$ at $9^{\text {th }}$ month. Repeated measure analysis of variance indicated that overall mean INR remained unchanged and was not statistically significant $(p>0.05)$. The mean INR of Group B at the time of discharge was $3.02 \pm 0.46$. Subsequent measurements were $2.96 \pm 0.69$ at $1^{\text {st }}$ month, $2.99 \pm 0.59$ at $2^{\text {nd }}$ month, $3.07 \pm 0.61$ at $3^{\text {rd }}$ month, $3.03 \pm 0.59$ at $6^{\text {th }}$ month and $3.10 \pm 0.52$ at $9^{\text {th }}$ month. Overall mean INR remained unchanged and statistically not significant. Similar pattern of INR was observed in group B patients but the difference in inter follow up period in both the groups were statistically not significant $(p>0.05)$. But there is significant difference throughout the follow up period between the two groups.

\section{Distribution of Prescribed Warfarin Dose of the Study Population}

The mean doses of warfarin prescribed for the patients in group $A$ at the time of discharge was $4.48 \pm 0.72 \mathrm{mg}$, at $1^{\text {st }}$ month $4.32 \pm 0.57 \mathrm{mg}$, at 2nd month $4.26 \pm 0.51 \mathrm{mg}$, at 3rd month $4.36 \pm 0.59 \mathrm{mg}$, at $6^{\text {th }}$ month $4.45 \pm 0.59 \mathrm{mg}$ and at the $9^{\text {th }}$ month $4.29 \pm 0.55 \mathrm{mg}$. Overall mean doses of warfarin remained unchanged and was not statistically significant $(p>0.05)$. Similar pattern of warfarin doses were observed in group B patients with a little higher dose but the difference in inter follow up period was not statistically significant $(p>0.05)$. There is significant difference between two groups at all follow up.

\section{Analysis of Post-operative Complications:}

In group A there were $8(16 \%)$ events of minor bleeding from nose, gum and skin. In group B that were $5(10 \%)$. One patient of group B died at the $3^{\text {rd }}$ month of follow-up due to intracranial hemorrhage. Chi-square test showed no statistically significant difference in bleeding episodes between two groups but data indicate that proportion of bleeding manifestation was higher in patients treated with warfarin plus aspirin group. One patient of group A developed transient ischemic attack. Among the three thromboembolic episodes of group B one manifested as transient ischemic attack, one developed peripheral thromboembolism and third one developed ischemic stroke with left sided hemiparesis. Analysis showed that no statistically significant difference between two treatment strategy but data indicate that proportion of thromboembolic manifestation was higher in patients treated with warfarin alone. In group A there were 0.02 / patient-year and in group B 0.08 / patient-year of thromboembolic events. One patient from group $B$ had died during the study at the $3^{\text {rd }}$ month of follow-up due to intracranial hemorrhage. Two patients of group B developed surgical site infection. They did not

Table-I

Distribution of study subjects according to age $(n=99)$

\begin{tabular}{lccc}
\hline Age (years) & Group $\mathrm{A}(\mathrm{n}=50)$ & Group $\mathrm{B}(\mathrm{n}=49)$ & p-value \\
\hline$\leq 20$ & $4(8.0)$ & $4(8.2)$ & \\
$21-30$ & $16(32.0)$ & $20(40.8)$ & \\
$31-40$ & $18(36.0)$ & $17(34.7)$ & \\
$>40$ & $12(24.0)$ & $8(16.3)$ & $0.292^{\text {ns }}$ \\
\hline
\end{tabular}

\# Un-paired $\mathrm{t}$ test was done to measure the level of significance, $\mathrm{ns}=$ non-significant.

Table-II

Distribution of study subjects according to sex $(n=99)$

\begin{tabular}{lccc}
\hline Gender & Group A(n=50) & Group B(n=49) & p-value \\
\hline Male & $21(42.0)$ & $26(53.1)$ & $0.270^{\text {ns }}$ \\
Female & $29(58.0)$ & $23(46.9)$ & \\
Total & $50(100.0)$ & $49(100.0)$ & \\
\hline
\end{tabular}

Tl Chi-square test was done to measure the level of significance, ns= non-significant. 
require any surgical intervention but prolonged the hospital stay. One patient of group B had mild paravalvular leakage. He was asymptomatic and was maintaining well. 3 patients in the group A had episodes of mild epigastric pain which relieved with two weeks course of proton pump inhibitor.

Table-III

Distribution of study subjects according to diagnosis in two groups ( $n=99)$

\begin{tabular}{lccc}
\hline Diagnosis & Group A(n=50) & Group B(n=49) & p-value \\
\hline MSR & $12(24.0)$ & $11(22.4)$ & $0.956^{\text {ns }}$ \\
MS & $25(50.0)$ & $24(49.0)$ & \\
MR & $13(26.0)$ & $14(28.6)$ & \\
Total & $50(100.0)$ & $49(100.0)$ & \\
\hline
\end{tabular}

Tा Chi-square test was done to measure the level of significance, ns= non-significant.

Table IV

Distribution of Post-operative INR at Follow Up

\begin{tabular}{|c|c|c|c|c|}
\hline INR range ${ }^{\#}$ & & Group $A(n=50)$ & Group $B(n=49)$ & p-value \\
\hline & $<1.8$ & $3(6.0)$ & $2(4.1)$ & \\
\hline & $1.8-2.4$ & $40(80.0)$ & $4(8.2)$ & \\
\hline \multirow[t]{5}{*}{ INR at discharge } & $2.5-3.5$ & $3(6.0)$ & $38(77.5)$ & \\
\hline & $>3.5$ & $4(8.0)$ & $5(10.2)$ & \\
\hline & Mean \pm SD & $2.25 \pm 0.44$ & $3.02 \pm 0.46$ & $<0.001^{\text {s }}$ \\
\hline & $<1.8$ & $7(14.0)$ & $3(6.1)$ & \\
\hline & $1.8-2.4$ & $37(74.0)$ & $13(26.5)$ & \\
\hline \multirow[t]{5}{*}{ INR at $1^{\text {st }}$ month } & $2.5-3.5$ & $4(8.0)$ & $27(55.1)$ & \\
\hline & $>3.5$ & $2(4.0)$ & $6(12.2)$ & \\
\hline & Mean \pm SD & $2.13 \pm 0.39$ & $2.98 \pm 0.69$ & $<0.001^{s}$ \\
\hline & $<1.8$ & $8(16.0)$ & $2(4.1)$ & \\
\hline & $1.8-2.4$ & $38(76.0)$ & $9(18.4)$ & \\
\hline \multirow[t]{5}{*}{ INR at $2^{\text {nd }}$ month } & $2.5-3.5$ & $2(4.0)$ & $34(69.3)$ & \\
\hline & $>3.5$ & $2(4.0)$ & $4(8.2)$ & \\
\hline & Mean \pm SD & $2.10 \pm 0.37$ & $2.99 \pm 0.59$ & $<0.001^{s}$ \\
\hline & $<1.8$ & $5(10.0)$ & $3(6.1)$ & \\
\hline & $1.8-2.4$ & $40(80.0)$ & $6(12.3)$ & \\
\hline \multirow[t]{5}{*}{ INR $3^{\text {rd }}$ month } & $2.5-3.5$ & $1(2.0)$ & $34(69.3)$ & \\
\hline & $>3.5$ & $4(8.0)$ & $6(12.3)$ & \\
\hline & Mean \pm SD & $2.20 \pm 0.46$ & $3.07 \pm 0.61$ & $<0.001^{s}$ \\
\hline & $<1.8$ & $11(22.0)$ & $2(4.1)$ & \\
\hline & $1.8-2.4$ & $36(72.0)$ & $10(20.4)$ & \\
\hline \multirow[t]{5}{*}{ INR at $6^{\text {th }}$ month } & $2.5-3.5$ & $2(4.0)$ & $33(67.3)$ & \\
\hline & $>3.5$ & $1(2.0)$ & $4(8.2)$ & \\
\hline & Mean \pm SD & $2.13 \pm 0.38$ & $3.03 \pm 0.59$ & $<0.001^{s}$ \\
\hline & $<1.8$ & $2(4.0)$ & $2(4.1)$ & \\
\hline & $1.8-2.4$ & $39(78.0)$ & $4(8.2)$ & \\
\hline \multirow[t]{3}{*}{ INR at $9^{\text {th }}$ month } & $2.5-3.5$ & $5(10.0)$ & $39(79.5)$ & \\
\hline & $>3.5$ & $4(8.0)$ & $4(8.2)$ & \\
\hline & Mean \pm SD & $2.34 \pm 0.46$ & $3.10 \pm 0.52$ & $<0.001^{s}$ \\
\hline
\end{tabular}

\# Un-paired $t$ test was done to measure the level of significance, $s=$ significant. 
Table-V

Distribution of Prescribed Warfarin Dose (mg) of the Study Population $(n=99)^{\#}$

\begin{tabular}{lcccccc}
\hline Group & At discharge $(\mathrm{mg})$ & $1^{\text {st }}$ month $(\mathrm{mg})$ & $2^{\text {nd }}$ month $(\mathrm{mg})$ & $3^{\text {rd }}$ month $(\mathrm{mg})$ & $6^{\text {th }} \mathrm{month}(\mathrm{mg})$ & $9^{\text {th }} \mathrm{month}(\mathrm{mg})$ \\
\hline Group A & $4.48 \pm 0.72$ & $4.32 \pm 0.57$ & $4.26 \pm 0.51$ & $4.36 \pm 0.59$ & $4.45 \pm 0.59$ & $4.29 \pm 0.55$ \\
Group B & $5.87 \pm 1.12$ & $5.83 \pm 1.10$ & $5.61 \pm 0.93$ & $5.42 \pm 0.69$ & $5.38 \pm 0.68$ & $5.33 \pm 0.51$ \\
p value & $<0.001^{\mathrm{s}}$ & $<0.001^{\mathrm{s}}$ & $<0.001^{\mathrm{s}}$ & $<0.001^{\mathrm{s}}$ & $<0.001^{\mathrm{s}}$ & $<0.001^{\mathrm{s}}$ \\
\hline
\end{tabular}

\# Un-paired $t$ test was done to measure the level of significance, $s=$ significant.

Table-VI

Post-operative Complications ( $n=99)$

\begin{tabular}{lccc}
\hline Complications & Group A(n=50) & Group B(n=49) & p-value \\
\hline Bleeding episodes & $8(16.0)$ & $5(10.2)$ & $0.392^{\mathrm{ns}}$ \\
Embolic episodes $^{¥}$ & $1(2.0)$ & $3(6.1)$ & $0.362^{\mathrm{ns}}$ \\
Infection $^{¥}$ & $0(0.0)$ & $2(4.1)$ & $0.242^{\mathrm{ns}}$ \\
Epigastric pain $^{*}$ & $3(6.2)$ & $0(0.0)$ & $0.117^{\mathrm{ns}}$ \\
Paravalvular leakage $^{¥}$ & $0(0.0)$ & $1(2.04)$ & $0.494^{\mathrm{ns}}$ \\
Death $^{*}$ & $0(0.0)$ & $1(2.04)$ & $0.494^{\mathrm{ns}}$ \\
\hline
\end{tabular}

ๆ Chi-square test, $¥$ fisher’s exact test, $s=$ significant.

\section{Discussion:}

In this study, a total of 99 patients were included to observe the safety and efficacy of combined low dose warfarin and aspirin in patients with mechanical mitral valve. Group A received warfarin in combination with $75 \mathrm{mg}$ aspirin. Group B received warfarin alone.

The age range of this study population was 18 to 58 years with similar mean ages in two groups (35.18 \pm 10.9 years for group $A$ and $32.94 \pm 8.81$ years for group B). In study conducted by Hayashi et al. ${ }^{10}$ patients who underwent mitral valve surgery had a mean age of $49.2 \pm$ 11.8 years. This difference may due to different etiological factors. In our country rheumatic mitral valve disease is still prevalent and usually occurs earlier than the degenerative valvular diseases which are more prevalent in western countries. Among the study population 47 (47.47\%) were male and $52(52.53 \%)$ were female. In a similar study between warfarin plus aspirin and warfarin conducted by Turpie et al. ${ }^{11}$ had male population of $52 \%$ and female population of $48 \%$ for all valve cases. Hayashi et al. ${ }^{10}$ in his study of mitral valve surgery had found $53.33 \%$ patients were suffering from MS, $27.77 \%$ from MR and $18.89 \%$ from MSR; not very different from our study. For group A $76 \%$ of INR values were within the target range and for group $B$ those were $69.67 \%$. Kontozis et al. ${ }^{12}$ in his series, with target of INR 2.5 to 3.5 , had been able to maintain target INR with $77 \%$ of time. Saour et al. ${ }^{13}$ in a trial of different intensities of anticoagulation in patients with prosthetic heart valves had reported that he had been able to maintain target INR of 2.3-2.7 at $86 \%$ of the visits.

Most of the minor bleeding occurred when the INR values were below 3.5. In group $A$, two patients had bleeding episode when INR was within target range (1.8-2.4), four patients had episode when INR was below 3.5 and two patients had bleeding episode when INR was above 3.5. In group $B$ there were 5 bleeding episodes of minor bleeding out of which two had occurred when INR was within target range (2.5-3.5) and two bleeding had occurred when INR was 3.6 to 4.9 and one had occurred when INR was unstable. The incidence of bleeding events in our study was 0.24 /patient year for group $A$ and 0.133 / patient year for group B. In the study reported by Yamak et al. ${ }^{14}$ the incidence of bleeding was $1.2 \%$ / patient year where the mean INR was $1.47 \pm 0.9$ (range 0.6-5.8) and $100 \mathrm{mg}$ of aspirin and dyprimadole had been given to the patients along with warfarin. In the series reported by Kontozis et al. ${ }^{12}$ bleeding episodes were $1.3 \%$ / patient year, where target INR was 2.0-2.5, mean INR was 1.88 \pm 0.54 with mean warfarin dose of $5.8 \pm 1.8 \mathrm{mg}$. Considering bleeding episodes as major or minor there were no uniformity among the studies. In combination therapy the bleeding episode is directly related to the dose of aspirin. In the study conducted with the aspirin doses of $500 \mathrm{mg}$ and higher had higher incidences of bleeding episodes. ${ }^{15}$ The study conducted regarding the effective dose of Aspirin had showed conclusion that for the prevention of vascular thromboembolic events low 
dose aspirin (around 100mg) is sufficient. Prescribing the larger doses only may precipitate unwanted major bleeding.

Thrombosis and embolism were also taken as the parameters for the outcome analysis in this study. Within the study period, total of 1 and 3 thromboembolic events occurs in group $A$ and group $B$ respectively. The linearized rate of thromboembolic events for Group A was 0.02 I patient year and for group B was 0.08/patient year $(p=0.362)$. The risk of embolism was 3.22 times higher in group B patients compared to group A patients. In both the group there were embolic events when the INR was within the target range. In Yamak ${ }^{14}$ series, the incidence of thromboembolism following MVR was $0.6 \%$ /patient year where the mean INR was $1.47 \pm 0.9$ (range 0.6-5.8) and $100 \mathrm{mg}$ of aspirin and dyprimadole had been given to patients along with warfarin. In our study there was no single episode of valve thrombosis. But in the study conducted by Yamak et al. ${ }^{14}$ (1999) the mean INR at time of valve thrombosis was $1.54 \pm 0.3$ (range 1.02-3.96).

Only one group B patient (2\%) developed paravalvular leak during 9 months of follow up. The incidence of paravalvular leakage, in large series, in isolated mitral valve is in the range of $0.2 \%$ to $0.5 \%$. ${ }^{16}$ There was no single prosthetic valve endocarditis in this series. However, in the study conducted by Banbury et al. ${ }^{16}$ the occurrence of endocarditis in isolated mitral valve was in the range of 0.5 to $1.0 \%$.

One patient had severe intolerance to aspirin, manifested with acute epigastric pain while in hospital. He was then treated with warfarin alone regime and included in Group B. During follow up period 3 patients from group A had complain of intermittent mild pain of gastritis. Their symptoms relived with two weeks of proton pump inhibitor. They were continued as group A population. There was no single episode of severe gastrointestinal bleeding in this study population.

\section{Conclusion:}

Our study showed that following the implantation of mechanical heart valve prosthesis in mitral position, a combination of low dose of warfarin and $75 \mathrm{mg}$ aspirin with an aim of target INR 1.8-2.4 provides satisfactory result in term of thrombosis, embolism and bleeding. This is important from two standpoints. First it has the potential to improve the care of the patients with prosthetic heart valves by reducing the thromboembolic events and second less intense anticoagulant regime plus low dose aspirin $(75 \mathrm{mg}$ ) is efficacious as high-intensity anticoagulant regime but with reduction in major bleeding events. Although to validate this conclusion a larger sample of patients and early and long-term outcome should be included in a study.

\section{Study Limitations:}

Several limitations of this study should be addressed-

- The number of study population was limited

- The short duration of the study period

- It was a single center study

\section{Acknowledgements:}

I owe my heartfelt gratitude and indebtedness to Professor Dr. Md. Kamrul Hasan, Professor, Department of Cardiac Surgery, NICVD for his active help, guidance and valuable suggestions.

\section{Disclosure of Interests:}

I have no potential conflict of interest with respect to the research, authorship, and/or publication of this article.

\section{References:}

1. Dong MF, Ma ZS, Ma SJ, Chai SD, Tang PZ, Yao DK, et al. Anticoagulation therapy with combined low dose aspirin and warfarin following mechanical heart valve replacement. Thrombosis Researsch. 2011;128 (5):e91-e94.

2. Garcia-Rinaldi R. Clopidogrel- ASA combination inhibits the thrombogenicity of St. Jude Medical Mechanical aortic prosthesis, guest commentary. Valve technology home. 2004;1:1-5.

3. Meschengieser SS, Fondevial CG, Frontroth J, Santarelli MT and Lazzari MA. Low-intensity oral anticoagulation plus low-dose aspirin versus highintensity oral anticoagulation: a randomized trial in patients with mechanical prosthetic heart valves. The Journal of Thoracic and Cardiovascular Surgery. 1997;113:910-916.

4. Butchart EG, Lewis PA, Grunkemeier GL, Kulatilaka $\mathrm{N}$, Breckenridge IM. Low risk of thrombosis and serious embolic events despite low-intensity anticoagulation- Experience with 1004 Medtronic Hall Valves. Circulation. 1988;78:166-177.

5. Cappelleri JC, Fiore LD, Brophy MT, Deykin D, Lau $\mathrm{J}$. Efficacy and safety of combined anticoagulation and antiplatelet therapy versus anticoagulation monotherapy after mechanical heart valve replacement: a meta-analysis. American Heart Journal. 1995;130:547-552.

6. Horstkotte D, Schulte HD, Bircks W, Strauer BE. Lower intensity anticoagulation therapy results in lower complication rates with the St. Jude 
mechanical prosthesis. Journal of Thoracic Cardiovascular Surgery. 1994;107:1136-1145.

7. Graubert TA. Disorder of hemostasis. In: Carey CF, Lee $\mathrm{HH}$, Woeltje KF, Schaiff RA, editors. Wasington manual of medical therapeutics. Philadelphia: Lippincot-Raven publisher; 1998.

8. Hirsh J, Fuster V, Ansell J and Jonathan L. American Heart Association / American College of Cardiology Foundation guide to warfarin therapy. Circulation. 2003;107:1692-1711.

9. Butchart EG, Payne N, Li HH, Buchan K, Mandana K, Grunkemeier GL. Better anticoagulation control improves survival after valve replacement. The Journal of Thoracic and Cardiovascular Surgery. 2002;123:715-723.

10. Hayashi JI, Nakazawa S, Oguma F, Miyamura H, Eguchi S. Combined warfarin and antiplatelet therapy after St. Jude medical valve replacement for mitral valve disease. Journal of American College of Cardiology. 1994;23:672-77.

11. Turpie AGG, Gent M, Laupacis A, Latour $Y$, Gunstensen J, Basile F, et al. A comparison of aspirin with placebo in patients treated with warfarin after heart-valve replacement. The New England Journal of Medcine. 1993;329:524-529.
12. Kontozis L, Skudicky D, Hopley MJ, Areli P. Long term follow-up of St. Jude Medical prosthetic in young rheumatic population using low-level warfarin anticoagulation: An analysis of the temporal distribution of causes of death. American Journal of Cardiology. 1998;81:736-739.

13. Saour JN, Sieck JO, Mamo LAR, Gallus AS. Trial of different intensities of anticoagulation in patients with prosthetic heart valves. The New England Journal of Medicine. 1990;322:428-432.

14. Yamak B, Iscan Z, Mavitas B, Ulus AT, Katircioglu SF, Tasmedir O, et al. Low dose oral anticoagulation and antiplatelets therapy with St. Jude Medical heart valve prosthesis. Journal of Heart Valve Disease. 1999;8:665-673.

15. Varadarajan P, Isaeff D, Pai RG. Prosthetic valve thrombosis presenting as an acute embolic myocardial infarction in a pregnant patient: issues on anticoagulation regimens and thrombolytic therapy. Echocardiography. 2006;23:1-20.

16. Bunbury MK. Acquired Aortic Valve Disease. In: Sellke FW, Nida PJD, Swansor S J, editors. Sabiston and Spencer Surgery of the Chest. $6^{\text {th }}$ ed. Philadelphia: Elsevier Saunder; 2005. 